\title{
HIVIAIDS Social Marketing \& Behavioural Change among Youths in Obubra Local Government Area of Cross River State, Nigeria
}

\author{
Enang, Ebingha E. (Ph.D) \\ Department of Sociology, University of Calabar, Calabar - Cross River State Nigeria \\ enangebingha@yahoo.com
}

Doi:10.5901/ajis.2014.v3n4p115

\begin{abstract}
The purpose of this study was to investigate into the issue of HIVIAIDS prevalence and behaviour change among youth in Obubra Local Government Area of Cross River State using the descriptive survey design and a sample size of 280 respondents on whom questionnaires were administered. Relevant literature was reviewed and with the use of Pearson coefficient (r), the result showed a strong relationship between social marketing and behaviour change among youths in the study area. It went further to recommend on the need to strengthen social marketing as a working strategy if the rampaging social menace of HIVIAIDS must be prevented among youths.
\end{abstract}

Keywords: HIVIAIDS, Social marketing, behaviour change, youths.

\section{Introduction}

Nigeria is a signatory to many international agreements to HIVIAIDS reduction which the Millennium Development Goals (MDGs) also aims to achieve through an improved standard of living and life expectancy. The country has also initiated major health interventions to reduce HIVIAIDS prevalence, including Reproductive and Child Health Interventions, Family Life HIV and AIDS Education (FLHE) and the multi-sectoral national response to HIV and AIDS epidemic (FMOH, 2008).

Like many other developing countries, Nigeria has passed through several phases in her response to the epidemic. The initial response was the establishment of the National Expert Advisory Committee on AIDS (NEACA) made up of mostly health professionals as Nigeria perceived the epidemic as a health problem. In 1988, this advisory board was replaced by the National AIDS and STDs Control Program (NASCP) under the coordination of the Federal Ministry of Health. In January 2000, the President in recognition of the need for a multi-sectoral response, established a Presidential Committee on AIDS (PCA) and later the National Action Committee on AIDS (NACA) now National Agency for the Control of AIDS.

Despite the above measures, sexual contact still remains the major mode of HIV transmission, especially amongst adolescents. According to the National Demographic Health Survey (NDHS) (2003), the median age of first sexual intercourse for boys in Nigeria is 17 years, while for girls is 17.9 years and it varies by region (the median age in the northwest and northeast zones is under 15 years). Although knowledge of HIV prevention is high in Nigeria, the level of utilization of services and practice of safer sex remains low, even with the increase in the HIV prevalence from 4.4 per cent to 4.6 per cent as revealed in the 2005 and 2008 Anti-Natal Clinic Survey (ANC) (FMOH, 2008).

In Cross River State, the HIV prevalence rate is 8.0 per cent as recorded by Anti-natal clinic survey data in 2008, and it is estimated to increase by 2 per cent per year and likely to double in about 10 years. According to the survey, the prevalence can be attributed to knowledge not translating to behaviour change as studies have shown that awareness level is high. Other reasons include traditional and religious opposition to some preventive methods like the use of condom, stigma and discrimination of persons living or affected with the virus and poor access to commodities and services (FMOH, 2003).

\section{Statement of the Problem}

The rate at which millions of people are being affected by the HIVIAIDS virus especially in developing countries like Nigeria is quite alarming. Amongst the most vulnerable are the youths and this has continued to constitute problem of great concern to healthcare planners as well as families, and other relevant agencies that do not have all the resources to implement specific HIVIAIDS awareness programmes targeted at youths in all geographical variations. 
With a continuous rate of increase in the spread of the inflation among youths despite the massive publicity through flyers, radio jingles, seminars, and workshops, activities of civil society organisations, non-governmental organisations and even faith-based organisations. There is the feeling that knowledge dissemination about the epidemic does not translate to a positive change in behaviour which is necessary if the epidemic must be stemmed. The paper therefore sets to examine how behaviour change can bring about a change in the reduction of the epidemic in Cross River State.

\section{Objective}

The main objective of this paper is to examine the relationship between HIV prevalence and knowledge on behaviour change among youths in Cross River State with particular interest in Obubra Local Government Area.

\section{Review of Relevant Literature}

There is no clear consensus existing regarding a universally acceptable term to describe how knowledge translates to behaviour change. Yet behaviour change never happens in a vacuum. Educationalists and sociologists alike have always focused on the role of information and education and more recently in life skills in bringing about behaviour change. There has always been the realization, no matter how vague and hazy, that structural and non-structural education are involved and indeed crucial in the change process (Okemba, 2004).

The Canadian Institute of Health Research (CIHR) in 2004 defined knowledge application as the process of moving what we learned to the actual applications of such knowledge in a variety of practice settings and circumstances. Champion and Leach (1989) examined three factors that help in knowledge applicability to include attitude, availability, and support. Availability examines the opportunity an individual has to access products or services in his or her environment or community. Support looks at what extent does an individual get encouraged from family, leaders, community, institutions to utilization of available products or services. Knowledge in the actual sense does not stop at awareness level but considers attitude, availability and support that translates awareness into practice (Harvey, 2009).

Global Forum for Health Research (2007) stated that too often, information meant to create awareness are undertaken by individuals and organisations without clear diagnosis of current needs and without prioritizing to ensure that those needs are met. It therefore means that basic parameters of activities should be designed to measure the objectives, nature, quality, and intensity of inputs, the audiences and the settings where knowledge is being communicated.

Stonburner, Low-Beer, Barnett and Whiteside (2000) found out in their study that there is an increase in the general knowledge of people in HIVIAIDS. The debate is, at what point do you say an individual has knowledge of a thing or an issue, is it at the awareness level or at the practice level? (Lloyd, 2007). This question has posed many challenges in determining knowledge of individual.

Mbulaiteye and Mahe (2002) reported that knowledge and behaviour change are interdependent and any separation is only an approximate. Thus, the process of behaviour change is multi-dimensional and non-linear. Behaviour change entails not only factors that contribute strongly to the practice. Recognizing that knowledge alone is usually insufficient to bring about behaviour change; the concept of life-skills has gained popularity and is another approach aimed at reducing underlying vulnerability to HIV.

The Cross River State Action Committee on AIDS (CRSACA) (2008) in its Epidemiological Response Synthesis Studies (EPRS) identified major sources of information on HIV to be the mass media and quickly added that mass media may aid in creating awareness but not provide an in-depth information on the disease. It therefore means that being aware does not necessarily mean having knowledge about a thing or an issue. An individual may be aware of an issue but until that awareness translates into practice, it is believed that the people lack knowledge of the same issue. Awareness is at the point of realization that a thing is in existence, while knowledge is at that point of not just realization but as well as putting it into practice or use. The question is, how does one measure knowledge?

Knowledge use is not a single discrete event occurring at one point in time; rather, it is a process consisting of several events (Richter, 1997). He went further to state that evaluating the use of knowledge can be complex and requires a multidimensional and systematic approach. USAID (2009) identified three dimensions to knowledge utilization to include knowledge utilization in the behavioural, cognitive and affective dimensions. It stated that the behavioural aspects measures by examining reported changes in the activities, practices, or policies; the cognitive aspect looks at beliefs about various aspects of the issue and affective dimension is concerned about the problem or issue and the targets' satisfaction with possible solutions. 


\section{Analytical Model}

Catania and Coates (1990) explained that AIDS risk reduction model developed in 1990, uses constructs from the health belief model, the social cognitive theory and the diffusion of innovation theory to describe the process individuals (or group) pass through while changing behaviour. Catania et al, identifies three stages involved in changing behaviour to include:

- Behaviour labelling.

- Commitment to change, and,

- Taking action.

He stated that behaviour labelling considers how knowledge about HIV transmission, perceived HIV susceptibility, as well as aversive emotions influence how people perceive AIDS. The commitment stage is shaped by four factors: perceptions of enjoyment, self-efficacy, social norms and aversive emotions, while taking action looks at aversive emotions, sexual communication, help-seeking behaviour and social factors that affect people's decision-making process (Catania, and Coates, 1990). Thus, if AIDS risk reduction model is to succeed three things must be considered, clients' risk assessment, perceptions of enjoyment or self-efficacy and clients' support to enact the change.

Agreeing with the model, Bandura, (1977) in the social cognitive theory looks at human behaviour as a continuous interaction between cognitive, behavioural and environmental determinants. He further identified the important roles played by vicarious, symbolic, and self-regulatory processes in psychological functioning and states that new behaviours are learned either by modelling the behaviour of others or by direct experience which is a function of self-efficacy and outcome expectancies. Emphasizing change to enhance motivation and reinforcement of risk reduction skills and selfefficacy, focuses on the experience people had. In the same vein, Kegeles (1990) identified that people are most likely to adopt new behaviours based on favourable evaluations of the idea communicated to them by other members whom they respect. That was why Kelly (1995) in explaining diffusion of innovation theory which recognizes that the best method to disperse messages with community is to use leaders who act as role models to change community norms, states that behavioural changes can be initiated when enough key opinion leaders adopt and endorse behavioural changes. When adopted the change will influence others to do the same and eventually diffuse the new norm widely within peer networks and to their subordinates. Based on diffusion of innovation theory, behaviours are changed and sustained within one's immediate social network, once it is perceived to be a social norm. Kalichman, (1998) noted that although each theory that made up the AIDS Risk Reduction Model is built on different assumptions, they all state that behavioural changes occur by altering potential risk-producing situations and social relationships, risk perceptions, attitudes, self-efficacy, beliefs, intentions and outcome expectations. Central to the theories is skills which are generally passed on to individuals in a process consisting of instruction, modelling, practice and feedback.

The theory of AIDS risk reduction model according to Aggleton (1996) has not been able to provide a clear cut understanding of the complexity of HIV transmission and control by overemphasis on individual behavioural change with a focus on the cognitive level thereby undermining the overall model capacity. Kelly, (1995) also argued out that in many cases, some behaviours such as sex are complicated, unclear and may not be thought through in advance and that societal norms, religious criteria, and gender power relations infuse meaning into behaviour, enabling positive or negative changes. However, the theory was very useful early in the epidemic to identify individual behaviours associated with higher rates of HIV transmission and guided the interest in the increased numbers of interventions surrounding individual behaviour. The theory is relevant to the present study, it implies that youths in Obubra Local Government Area are likely to change their behaviour from indulging in risky sexual activities to healthier life styles once they perceive the new behaviour to be accepted norm. It implies that through voluntary counselling services in the areas the potential riskproducing situations and social relationships youths have been able to acquire knowledge for behaviour change.

The theory also implies that through the activities of on-going communication campaigns and voluntary HIV counselling services are desirable as a means of integrating information and attitudinal change in youths in Obubra Local Government Area of Cross River State, Nigeria.

\section{Methodology}

The research utilizes a descriptive research design to study the relationship between HIVIAIDS prevalence and behavioural change among youths in Obubra Local Government Area. The data set comprise 280 respondents who were randomly selected from the study area. Pearson coefficient $(r)$ was employed to measure the relationship between social marketing and behaviour change. 


\section{Result and Discussion}

A total of 280 youths which comprise 152 males (54.3\%) and 128 females (45.7\%) were used for the study. Out of these number, 190 (67.9\%) were single, 80 (28.6\%) were married, 6 (2.1\%) were divorce and 4 (1.4\%) were separated.

Pearson Product Moment Correlation Coefficient Analysis of the relationship between social marketing and behaviour change

\begin{tabular}{|c|c|c|c|c|}
\hline Variable & $\begin{array}{l}\sum y \\
\sum x\end{array}$ & $\begin{array}{l}\sum y^{2} \\
\sum x^{2}\end{array}$ & $\sum x y$ & r-cal \\
\hline $\begin{array}{l}\text { Behaviour Change (y) } \\
\text { Social marketing }\end{array}$ & $\begin{array}{l}4780 \\
7820\end{array}$ & $\begin{array}{l}100560 \\
149800\end{array}$ & 107840 & 0.515 \\
\hline
\end{tabular}

The result of the statistical analysis revealed that social marketing significantly relate to knowledge on behaviour change. Since the value of "r" was positive, it indicates that the more social marketing was made, the healthier the lives of youths. This finding is support by Ntozi, Mulindwa, Ahimbisibore, Ayiga and Odwee (2003) who state that HIVIAIDS epidemic has changed the sexual behaviour of high risk groups. This is also in agreement with Steven (1998) findings that, in response to the HIV and AIDS epidemic, social marketing programmes have made condoms accessible, affordable and acceptable to low income populations and high risk groups which has significantly contributed to the reduction of the incidence of HIVIAIDS. It is therefore recommended that social marketing should be strengthened as a working strategy if HIVIAIDS must be prevented especially among youths.

\section{References}

Aggleton, P. (1996) Global Priorities for HIVIAIDS Intervention Research. International Journal of STD \& AIDS 1996; 7(Suppl.2): 13-16 Bandura, A. (1977) Social Learning Theory. Prentice-Hall, Inc.: Englewood Cliffs, New Jersey

Canadian Institute of Health Research (2004). Knowledge Translation Strategy 2004-2009: Innovation in Action. Retrieved September 9 , 2006 from http://www.cihr-irsc.gc.ca/e/26574.html

Catania, J. and Coates, T. (1990) Towards an understanding of risk behaviour: An AIDS Risk Reduction Model (ARRM). Health Education Quarterly, 17(1): 53-72

Champion, V. L., and Leach, A. (1989) Variables related to research utilization in nursing: An empirical investigation. Journal of Advanced Nursing, 14, 705-710

CRSACA (2008) Cross River State HIVIAIDS Epidemiology, Response and Policy Synthesis, 2008. CRSACA, NACA and World Bank Federal Ministry of Health (2008) National HIVIAIDS and Reproductive Health Survey, 2008. Federal Ministry of Health, Abuja, Nigeria Federal Ministry of Health (2008) National HIVIAIDS and Reproductive Health Survey, 2003. Federal Ministry of Health, Abuja, Nigeria Global Forum for Health Research (2007) Research Issues in Sexual and Reproductive Health for Low and Middle Income Countries Harrey, D. (2009) Changing Adolescent Beliefs about Premarital Sex, Health Comm., 20, 195-206

Kalichman, S. (1998) Preventing AIDS: A Sourcebook for Behavioural Interventions. 1998 Laurence Erlbaum Associates Inc., Pubs. 10 Industrial Avenue, Mahwah, N.J.

Kegeles, S. (1990) Towards an Understanding of Risk behaviour: An AIDS Risk Reduction Model. Health Education Quarterly, 18(1): 23-32

Kelly, J. (1995) Changing HIV risk behaviour: practical Strategies, The Guilford Press, 72 Spring Street, New York.

Lloyd, C. B. (2007) The Role of Schools in Promoting Sexual and Reproductive Health among Adolescents in Developing Countries. Poverty, Gender and Youth Working Paper no. 6, New York: Population Council

Mbulaiteye, S. M., Mahe, C. (200) Declining HIV-I incidence and associated prevalence over 10 years in rural population in south-west Uganda: A cohort study. Lancet, 360, 41-44

Ntozi, V., Mulindwa, O., Ahimbisibore, J., Ayiga, G, and Odwee, R. (2003) Economic and Human Biology: Determinants of Teenage Pregnancies: The Case of Busia District in Kenya, Vol. 5, Issue 2, pp. 322-339

Okemba, O. (2004) Horizon: Turnout overwhelms VCTs. African woman and Child Feature Services

Richter, L. (1997) Street Children and HIVIAIDS, AIDS Bulletin, Dec., 6, 4, 4-6

Richter, L. M. and Swart-Kruger, J. 91995) AIDS-Risk among street children and youth: Implications for intervention. In, South African Journal of Psychology, Mar., 25(1): 31-38

Stevens, P. (1998) Participatory action research for sustaining individual and community change: A model of HIV prevention education. AIDS Education Prevention, 10(5): 387-402

Stoneburner, R., Low-Beer, D., Barnett, T. and Whiteside, A. (2000) "Enhancing HIV Prevention in Africa: Investigating the Role of Social Cohesion on Knowledge Diffusion and Behaviour Change in Uganda" XIIIth International AIDS Conference, July, Durban, South Africa

USAID (2009) Report on the Global AIDS Epidemic. US 